\title{
Design and Realization of the E-learning Evaluation Based on TEST
}

\author{
Shao-jing Zhou ${ }^{1, a}$, Peng-rui Qiu ${ }^{2, b}$, Wen Chen ${ }^{1, c}$ and Zhao Kun-can ${ }^{3, d}$ \\ ${ }^{1}$ Faculty of Computer Information, Kunming Metallurgy College,Kunming, China \\ ${ }^{2}$ Training Department, Kunming Metallurgy College, Kunming, China \\ ${ }^{3}$ Affairs Office, Kunming Metallurgy College, Kunming, China \\ aemail Joesj@qq.com, bemail 80420631@qq.com, 'email 411616621@qq.com, ${ }^{\text {demail }}$ \\ zhaokc@126.com
}

\begin{abstract}
Keywords: Online Evaluation System; E-learning Evaluation Model; System Test; E-learning Evaluation Quota
\end{abstract}

Abstract. Design and development of online evaluation system is the current hot research about the online learning evaluation, but the current implementation of the evaluation systems are mostly based on the given evaluation model to develop an experimental system or build a technology framework, which do not put into practice. The online learning is a complex system, in order to avoid e-learning implementation and development are disturbed by the negative factors, it is imminent that peoples establish a set evaluation system and quality management standard that are from planning to design, development, implementation, monitoring and evaluation. Try to give e-learning evaluation quota, on the basis of above establish online evaluation model and realize its system, the system is reliable and effective after the test.

\section{Introduction}

In the present information age, virtual learning, mobile learning, ubiquitous learning and so on are all relied on the continuous development and evolution of e-learning. About data show that in the last ten years, the number of online registered students in the world accounted for the proportion of higher education has more than 25\% [1]. Massachusetts Institute of Technology Sloan business school survey data show that in 2010 the United States registered online learning college students than in 2009 more than one million [2]. Domestic aspects, by 2010, network education of the undergraduate and specialist online students had 4531000 people, year enrollment is the total number of college admissions 25\%[3]. With the development of network technology and the arrival of the digital era, online learning will become the important way of learning in the future [4].

The e-learning needs some restraint mechanism and monitoring mechanism to guarantee the learning quality. Learning evaluation is an important way to realize the learning monitor, through the value judgment of students learning process and the results, it can study and promote the learning quality[5].In the process collects objective datum, information and data of the e-learning process in the network environment to quantitatively analyze for learning attitude, behavior and results, and judge the e-learning quality, still exists some problems[6]:incomplete evaluation information, existing evaluation system is very difficult to record and monitor the e-learning effect; pay attention to the results and despise the learning process; evaluation subject is single; objectivity tests are too much; evaluation comprehensiveness is not high, for example, when separately evaluates for some factor of influence, how to consider other factors to learners' influence such as the learners' participation, assignments, discussions etc. In addition, narrowly understanding of the e-learning dynamic mechanism and simply treatment of the e-learning behavior are more prominent, design and development of the evaluation system focus on learning behavior monitor, at the same time it should be emphasized that learning motivation of the learners are excited [7].In view of this situation, it is necessary to design effective learning process monitoring system by using the information technology [8]. 


\section{E-learning Evaluation Quota}

Research of online learning evaluation of the comprehensive evaluation total-evaluation method is based on the TEST, and evaluation subject is composed of teachers, engineers and students. The e-learning and classroom teaching parallel execution, it gets the total score of the course according to online learning evaluation and online test at the end of the term, by which generates course credits after the end of learning, and compares with MOOC have in common.

In the "state modern distance education resource construction technical specification", it recommends that student evaluation system of the remote teaching system should include: student to choose learning con-tent depth degree evaluation, student assignment evaluation, question answering evaluation for students, discussion evaluation, examination evaluation that is composed of test difficulty, test reliability and test score, and attitude evaluation. According to this, construct the evaluation quota of the online learning, the course content is one of the evaluation quotas to carry out evaluation in real time for learning process and content effect; with learning rate of progress automatically set test questions, after answer correction and continue to learn, and at the same time, after each learning modules is finished, require the grade of the corresponding thematic test is up to standard. Evaluation task quota, each task completes in three stages, and the corresponding there are learning evaluation of the three stages, the evaluation subject consists of engineers, teachers and students. The evaluation quota of the question answering, through the online message and learning forum to solve answering questions and discussion for learning difficulties, teachers help students, students can also. The discussion evaluation quota, the curriculum uses the theme activity and the forum replies to implement attitude evaluation of the student participation. Test quota, make the test system carry out result assessment to students, first the system establishes the checked test syllabus; secondly create question bank and check questions one by one including ownership of the examination point, rationality of the question difficulty, question scientificalness etc; finally after defined test paper, check the coverage range of the examination points, the difficulty of the test paper etc. The quotas of the course document learning and the micro learning can improve the learning quality and solve effectively the problems of the practical application.

To achieve issues of the incomplete evaluation in-formation and other issues of the end of assessment and format assessment, need make using of a variety of evaluation tools, a variety of evaluation subjects, a variety of learning dynamic excitation mechanism to evaluate the e-learning. Therefore, evaluation should include thematic test evaluation called E-TT for short, the task learning evaluation called E-TL, evaluation of document learning process call E-DLP, evaluation of course learning process called E-CLP, evaluation of micro course e-learning called E-ME ,evaluation of activity theme called E-AT and evaluation of discussion and interaction called E-DI. In addition, discussion evaluation contains evaluation contents of incentive innovation.

\section{Implementation Model of Evaluation}

The online learning evaluation model based on TEST is implemented formula (1) and (2).

$$
\begin{aligned}
\text { TEST }_{0} & =E_{t t}+E_{t l}+E_{d l p}+E_{c l p}+E_{m e}+E_{a t}+E_{d i} \\
\text { TEST } & =\left\{\begin{array}{l}
\text { Test }_{0}, \text { Test }_{0}<=99 \\
99, \text { Test }_{0}>99
\end{array}\right.
\end{aligned}
$$

Evaluation of Thematic Testing. The thematic test model $\mathrm{T}$ follows as formula (3). In formula (3), the thematic test of the No. I learning situation is composed of $f_{s i}, f_{m i}, f_{j i}, f_{b i}, f_{a i}$, among them which $f_{a i}$ can be an option, $f_{s i}$ is single choice function, $f_{m i}$ is multiple choice function, $f_{j i}$ is judgment function, $f_{b i}$ is function of the fill in the blanks and $f_{a i}$ is application function.

$$
T=\left\{E_{t t_{i}} \mid E_{t t_{i}} \in\left\{f_{s_{i}}, f_{m_{i}}, f_{j_{i}}, f_{b_{i}},\left[f_{a_{i}}\right]\right\}\right\}, i \in(1,2, \cdots, n)
$$


Calculating grade method of the user's thematic test follows as formula (4). In formula (4), $P P S_{i}$ is number I learning situation test points corresponding thematic test and its pass mark proportion, a learning situation test score $=$ set fraction $\mathrm{s} 0 /$ total of the learning situation.

$$
E_{t t}=s_{0} / s_{M} \times \sum_{i=1}^{m} P P S_{i}
$$

Task Learning Evaluation. In E-TL, students, teachers and engineers evaluate assignment by student submission after task completed. E-TL can support student upload works, schemes, comprehensive application document, the implementation of each task divided into three stages, evaluation rules can be defined according to different course, and then the score module of the document gives evaluation result. The demand model of the E-TL follows as formula (5). In formula (5), $S_{i}, T_{j}, E_{k}$ respectively represent evaluation grade of the $i$ student, the $j$ teacher, the $k$ engineer; $P_{1}$, $P_{2}$ and $P_{3}$ are the corresponding proportion coefficient; $n, m$ and $y$ respectively are the numbers of the student mutual, teachers evaluation, expert evaluation.

$$
\begin{aligned}
& E_{t l}=\left\lceil\left(\sum_{i=1}^{n} S_{i} \times P_{1}\right) / n+\sum_{j=1}^{m}\left(T_{j} \times P_{2}\right) / m+\sum_{k=1}^{y}\left(E_{k} \times P_{3}\right) / y\right\rceil \\
& S_{i}=\left(s_{1}+S_{2}+S_{3}\right) / 3, T_{i}=\left(t_{1}+t_{2}+t_{3}\right) / 3, E_{i}=\left(e_{1}+e_{2}+e_{3}\right) / 3
\end{aligned}
$$

In formula (6), $S_{1}, S_{2}$ and $S_{3}$ represent any student's evaluation scores of the initial, middle and final three stages about task implementation process; $T_{i}$ and $E_{i}$ are similarly.

Evaluation of Document Learning Process. E-PD is any user's evaluation of the document learning process, learning technology document by evaluation criteria called $E C$, real-time monitor called RTM and document evaluation upper limit called DEUL to evaluate. In addition, real-time generate questions according to itself, and then evaluate by answer data.

$$
P_{t p}=\sum_{i=1}^{n} f\left(x_{i}\right) \times p_{i}, x_{i} \in[P|C| M \mid], p_{i} \in[0,1]
$$

In formula (7), $P_{t p}$ represents real-time problems, test questions are generated by the current evaluation content to determine, namely $x_{i} \in[P|C| M]$; $P$ stands for document evaluation problem sets, $C$ represents the problem of curriculum evaluation set, $M$ on behalf of micro course evaluation set. Therefore, we can obtain formula (8), (9), (10).

$$
\begin{aligned}
& C=\left[C_{1}, C_{2}, \cdots, C_{j}, C_{m}\right], M=\left[M_{1}, M_{2}, \cdots, M_{j}, M_{m}\right], P=\left[P_{1}, P_{2}, \cdots, P_{j}, P_{m}\right] \\
& E_{p d}= \begin{cases}\sum_{i=1}^{n} E C_{i} \times R T M \times \sum_{i=1}^{n} f\left(x_{i}\right) \times p_{i i}, & E P D \leq D E U L, n \geq 5, R T M_{i}={ }^{P_{0}} / n \\
D E U L \times \sum_{i=1}^{n} f\left(x_{i}\right) \times p_{i} & , E P D>D E U L\end{cases}
\end{aligned}
$$

$R T M_{i}=t>=0.6 T_{i} ? 1: 0$

Among them, $P_{0}$ is the total score of the E-PD, the $E C_{i}$ and $R T M_{i}$ are the evaluation scores and real-time monitoring parameters of document I. In formula (10), $T_{i}$ represents time constant of user online learning document, learning time over $60 \%$ of the $T_{i}$ can be identified for effective learning, and then there is $T_{i} \in\left\{T_{1}, T_{2}, \cdots, T_{n}\right\}$.

E-CLP and E-ME. The process evaluation of course learning of any user's learning situation called $P E C$, which is consisted of segmented evaluation called $S E$, course real-time monitoring called CRTM and course evaluation upper limit called CEUL. We can obtain formula (11), (12).

$$
E_{\text {clp }}=\left\{\begin{array}{l}
\sum_{i=1}^{n} f\left(x_{i}\right) \times p_{i} \times S E_{i} \times C R T M, P E C<C E U L \\
C E U L \times \sum_{i=1}^{n} f\left(x_{i}\right) \times p_{i},, P E C \geq C E U L
\end{array}\right.
$$


$\mathrm{CRTM}_{i}=t>=0.6 T_{i} ? 1: 0$

In formula (12), $T_{i}$ represents time constant of user online learning courseware, learning time over $60 \%$ of the $T_{i}$ can be identified for effective learning, and then there is $T_{i} \in\left\{T_{1}, T_{2}, \cdots, T_{n}\right\}$. E-ME is divided into the project micro course called PM and curriculum micro course called $\mathrm{M}$, so that more consistent with the combination of theory and practice. The calculation method of evaluation follows as formula (13).

$$
E_{m e}=\sum_{i=1}^{n} P M_{i} \cdot \text { scorex } f\left(x_{i}\right) \times p_{i} t / T_{i}+\sum_{j=1}^{m} M_{j} . \operatorname{scorex} f\left(x_{i}\right) \times p_{i} t / T_{j}
$$

In formula (13), $P M_{i}$ and $M_{j}$ respectively represent project micro course $i$ and curriculum micro course $j$, and respectively represent $P M_{i}$ and $M_{j}$ corre-sponding to the learning time, and $t$ is learning micro course time.

E-AT and E-DI. The definition of the E-AT is followed as formula (14):

$$
E_{a t}=\sum_{i=1}^{n} A T_{i}=\sum_{i=1}^{n} a t_{i} \cdot \text { score }
$$

In formula (14), $A T_{i}$ is the activity evaluation result, and the activity number is set according to need. The evaluation score of activity $I$ is represented as $a t_{i . s c o r e}$. The definition of any user performed the E-DI is followed as formula (15):

$$
E_{d i}=\left\lceil\sum_{i=1}^{n} D I+\sum_{j=1}^{m} p\left(x_{j}\right) \text { value } 40 ? \sum_{i=1}^{n} D I+\sum_{j=1}^{m} p\left(x_{j}\right)\right. \text { value40 }
$$

In formula (15), $D I_{i}$ is the discussion evaluation result, and the activity number is set according to need. The evaluation reference score of discussion $I$ is 0.5 score; represents the evaluation result of added post $j$, further expressed $p(x)$.value $\in[10,5,3]$. $D_{0}$ is three incentive points, so $D_{0} \in[10,5,3]$, namely when the students add innovative learning content and has a detailed diagram, $p(x)$.value $=10$; after participate in discussion and post, and if be approval, $p(x)$.value $=5$;if active positive post and post click rate more than 50 times, $p(x)$.value $=3$. When $p(x)$.mark=true, $p(x)$.value $=10$; when $p(x)$.confirm $=$ true, $p(x)$.value $=5$; when $p(x)$.count $>=50, p(x)$. value $=3$.

\section{Implementation and Test Analysis}

System Implementation. In pseudo code of the algorithm, ett represents the thematic evaluation, etl represents the task evaluation, epd represents evaluation of document learning process, eclp represents evaluation of course learning process, ems represents evaluation of micro course, eat represents activity evaluation, and edi represents a parameter of the discussion evaluation. The algorithm described in detail as following.

while (user.login==true)

if (ett==true) according to formula (3) generate thematic questions; test monitoring \| client implementation. After test finished, record unit test scores; according to formula (4) compute score and save into database; end if

if (etl==true) submit task implementation reports; student mutual assessment, teacher evaluation, engi-neering evaluation; use formula (6) to compute results of each task evaluation; use formula (5) to calculate the task evaluation of a student; end if

if(epd==true)learn document, record monitoring status; calculate values of the $E C_{i} \times R T M_{i}$ and formula (10);record scores have learned; use formula (7),(8) and (9) to compute scores of the document learning evaluation; end if

if(eclp==true) learn courseware, record monitoring status; compute values according to $C E C_{i} \times$ $C R T M_{i}$ and formula (12); record scores have learned course-ware; use formula (7), (8) and (11) to calculate scores of the courseware learning evaluation; end if 
if(ems==true)learn project micro course $\|$ curriculum micro course; $P M_{i}$.score $\times t \div T_{i} \|$ $M_{i}$.score $\times t \div T_{i}$, compute project \|| micro course scores, and record; use (7), (8) and (13) to count scores of the micro course learning evaluation; end if

if (eat==true) participate in the theme activities; record the theme activities; use formula (14) to calcu-late scores of subject activity evaluation; if end

if (edi==true)discuss or reply topic; record reply situation; send post; calculate $p(x)$.value according to formula (15);record post evaluation results; count discussion evaluation results; if end.

Use formula (1) and (2) to gather statistics user online learning evaluation scores.

Test and Analyze. Test mainly tests student's various learning behavior feedback. The evaluation set of the test course is: 8 chapter course wares, score 16, and each chapter evaluation threshold 30 minutes and 20 questions. This code is E-courseware; (2) articles of the course and knowledge has 84 papers, article threshold 5, 15 questions per paper, this code: E-article; (3) the E-TT, eight learning units, scores 16 points, this code: E-test; (4) the E-TL , four learning tasks, 9 points per task, After finished the stage of each task obtaining 3 points, the code: E-task; (5) the E-ME,3 project micro courses, setting 3 points, 30 minutes pre micro video. 6 course micro courses, setting 6 points, 10 minutes per video. Per video are 10 questions. The code: E-micro-course; (6) the E-AT, 37 activities, 0.5 points per activity, the code: E-activity; (7) the E-DI, 0.1 points per reply, the code: E-discussion. Test and analyze with learning behavior of Joe students, Joe's E-courseware results are shown as Table 1. His E-article shows as Table 2.Joe has completed thematic test of 8 units, the E-test evaluation results are shown as Table 3; his E-task valuation results are shown as Table 4. Machine evaluation and artificial evaluation exists a slight error is mainly that sys-tem calculates third decimal place doesn't have four to five homes, but after rounding results don't affect; his E-micro-course results are shown as Table 5. Joe's activities are 8 times, evaluation of artificial and ma-chine both are 4 points; the data of discussion evaluation: reply and confirmation 1,1 post and click number more than 50, 24 times reply, both evaluation are 10 points. Through the analysis of the above instance data, the results of Joe's learning evaluation are both consistent analysis by artificial and machine means. So the results of the system are reliable and effective.

Table 1. Evaluation Data of Joe’s e-courseware

\begin{tabular}{|c|c|c|c|c|c|c|}
\hline $\begin{array}{c}\text { Evaluation } \\
\text { project }\end{array}$ & $\begin{array}{c}\text { Time } \\
\text { threshold }\end{array}$ & $\begin{array}{c}\text { Effective } \\
\text { time }\end{array}$ & $\begin{array}{c}\text { Question } \\
\text { threshold }\end{array}$ & $\begin{array}{c}\text { Answer } \\
\text { correct } \\
\text { number }\end{array}$ & $\begin{array}{c}\text { Machine } \\
\text { scores }\end{array}$ & $\begin{array}{c}\text { Artificial } \\
\text { scores }\end{array}$ \\
\hline C-No1 & $30 \mathrm{mins}$ & $21 \mathrm{mins}$ & 20 & 20 & 0 points & 0 points \\
\hline C-No2 & $30 \mathrm{mins}$ & $34 \mathrm{mins}$ & 20 & 20 & 2 points & 2 points \\
\hline C-No3 & $30 \mathrm{mins}$ & $50 \mathrm{mins}$ & 20 & 20 & 2 points & 2 points \\
\hline C-No4 & $30 \mathrm{mins}$ & $72 \mathrm{mins}$ & 20 & 18 & 0 points & 0 points \\
\hline C-No5 & $30 \mathrm{mins}$ & $66 \mathrm{mins}$ & 20 & 20 & 2 points & 2 points \\
\hline C-No6 & $30 \mathrm{mins}$ & $55 \mathrm{mins}$ & 20 & 20 & 2 points & 2 points \\
\hline C-No7 & $30 \mathrm{mins}$ & $70 \mathrm{mins}$ & 20 & 20 & 2 points & 2 points \\
\hline C-No8 & $30 \mathrm{mins}$ & 98 mins & 20 & 20 & 2 points & 2 points \\
\hline & Subtotal & & 12 points & 12 points \\
\hline
\end{tabular}


Table 2. Evaluation Data of Joe's E-article

\begin{tabular}{|c|c|c|c|c|c|c|c|}
\hline $\begin{array}{c}\text { Evaluation } \\
\text { project }\end{array}$ & $\begin{array}{c}\text { Question } \\
\text { threshol } \\
\text { d }\end{array}$ & $\begin{array}{c}\text { Evaluation } \\
\text { threshold }\end{array}$ & $\begin{array}{c}\text { Effectiv } \\
\text { e time }\end{array}$ & $\begin{array}{c}\text { Click } \\
\text { number }\end{array}$ & $\begin{array}{c}\text { Correct } \\
\text { number }\end{array}$ & $\begin{array}{c}\text { Machine } \\
\text { scores }\end{array}$ & $\begin{array}{c}\text { Artificia } \\
\text { l scores }\end{array}$ \\
\hline A-No23 & 15 & $\begin{array}{c}25 \text { mins, interval } \\
2 \text { mins, clicks }>=8\end{array}$ & 38 mins & $\begin{array}{c}145 \\
\text { times }\end{array}$ & 15 & 0 points & 0 points \\
\hline A-No27 & 15 & $\begin{array}{c}25 \text { mins, interval } \\
2 \text { mins, clicks }>=8\end{array}$ & 53 mins & $\begin{array}{c}213 \\
\text { times }\end{array}$ & 15 & 2 points & 2 points \\
\hline A-No45 & 15 & $\begin{array}{c}25 \text { mins, interval } \\
2 \text { mins, clicks }>=8\end{array}$ & 41 mins & $\begin{array}{c}109 \\
\text { times }\end{array}$ & 15 & 2 points & 2 points \\
\hline A-No78 & 15 & $\begin{array}{c}25 \text { mins, interval } \\
2 \text { mins, clicks }>=8\end{array}$ & 34 mins & $\begin{array}{c}172 \\
\text { times }\end{array}$ & 10 & 0 points & 0 points \\
\hline A-No12 & 15 & $\begin{array}{c}25 \text { mins, interval } \\
2 \text { mins, clicks }>=8\end{array}$ & 27 mins & 61 times & 15 & 2 points & 2 points \\
\hline
\end{tabular}

Table 3. Evaluation data of Joe's E-test

\begin{tabular}{|c|c|c|c|c|c|}
\hline $\begin{array}{c}\text { Evaluation } \\
\text { project }\end{array}$ & Total score & $\begin{array}{c}\text { Evaluation } \\
\text { threshold }\end{array}$ & Actual score & $\begin{array}{c}\text { Machine } \\
\text { scores }\end{array}$ & $\begin{array}{c}\text { Artificial } \\
\text { scores }\end{array}$ \\
\hline T-No1 & 100 points & $60 \%$ & 54 points & 0 points & 0 points \\
\hline T-No2 & 100 points & $60 \%$ & 81 points & 2 points & 2 points \\
\hline T-No3 & 100 points & $60 \%$ & 77 points & 2 points & 2 points \\
\hline T-No4 & 100 points & $60 \%$ & 84 points & 2 points & 2 points \\
\hline T-No5 & 100 points & $60 \%$ & 73 points & 2 points & 2 points \\
\hline T-No6 & 100 points & $60 \%$ & 95 points & 2 points & 2 points \\
\hline T-No7 & 100 points & $60 \%$ & 47 points & 0 points & 0 points \\
\hline T-No8 & 100 points & $60 \%$ & 77 points & 2 points & 2 points \\
\hline
\end{tabular}

Table 4. Evaluation data of Joe's E-task

\begin{tabular}{|c|c|c|c|c|c|c|}
\hline Project & $\begin{array}{c}\text { Time } \\
\text { threshold }\end{array}$ & $\begin{array}{c}\text { Effective } \\
\text { time }\end{array}$ & $\begin{array}{c}\text { Question } \\
\text { threshold }\end{array}$ & $\begin{array}{c}\text { Correct } \\
\text { number }\end{array}$ & $\begin{array}{c}\text { Machine } \\
\text { scores }\end{array}$ & Artificial scores \\
\hline C-No1 & 30 mins & 21 mins & 20 & 20 & 0 points & 0 points \\
\hline C-No2 & 30 mins & 34 mins & 20 & 20 & 2 points & 2 points \\
\hline C-No3 & $30 \mathrm{mins}$ & 50 mins & 20 & 20 & 2 points & 2 points \\
\hline C-No4 & $30 \mathrm{mins}$ & $72 \mathrm{mins}$ & 20 & 18 & 0 points & 0 points \\
\hline C-No5 & $30 \mathrm{mins}$ & $66 \mathrm{mins}$ & 20 & 20 & 2 points & 2 points \\
\hline C-No6 & $30 \mathrm{mins}$ & $55 \mathrm{mins}$ & 20 & 20 & 2 points & 2 points \\
\hline C-No7 & $30 \mathrm{mins}$ & $70 \mathrm{mins}$ & 20 & 20 & 2 points & 2 points \\
\hline C-No8 & $30 \mathrm{mins}$ & $98 \mathrm{mins}$ & 20 & 20 & 2 points & 2 points \\
\hline
\end{tabular}


Table 5. Evaluation data of Joe’s E-micro-course

\begin{tabular}{|c|c|c|c|c|c|c|c|c|}
\hline \multirow{2}{*}{$\begin{array}{c}\text { Evaluation } \\
\text { project }\end{array}$} & Student evaluation & Teacher evaluation & Engineer evaluation & Machin & Artificia \\
scores & $\begin{array}{c}\text { Student } \\
\text { number }\end{array}$ & scores & $\begin{array}{c}\text { Teacher } \\
\text { number }\end{array}$ & scores & $\begin{array}{c}\text { Engineer } \\
\text { number }\end{array}$ & scores & l scores \\
\hline \multirow{3}{*}{ T-No1 } & 63 & 29 & 11 & 4 & 6 & 3 & 2.3 & 2.31 \\
\cline { 2 - 9 } & 53 & 20 & 8 & 3 & 5 & 2 & 2.57 & 2.61 \\
\cline { 2 - 9 } & 67 & 26 & 11 & 4 & 7 & 3 & 2.55 & 2.55 \\
\hline \multirow{3}{*}{ T-No2 } & 90 & 30 & 9 & 4 & 5 & 3 & 2.3 & 2.34 \\
\cline { 2 - 9 } & 69 & 23 & 8 & 3 & 7 & 3 & 2.66 & 2.67 \\
\cline { 2 - 9 } & 90 & 30 & 9 & 3 & 8 & 3 & 2.88 & 2.89 \\
\hline \multirow{4}{*}{ T-No3 } & 90 & 30 & 7 & 3 & 6 & 3 & 2.44 & 2.44 \\
\cline { 2 - 9 } & 90 & 30 & 7 & 3 & 7 & 3 & 2.55 & 2.55 \\
\cline { 2 - 9 } & 90 & 30 & 8 & 3 & 7 & 3 & 2.66 & 2.67 \\
\hline \multirow{3}{*}{ T-No4 } & 90 & 30 & 9 & 4 & 7 & 3 & 2.52 & 2.53 \\
\cline { 2 - 9 } & 90 & 30 & 10 & 4 & 5 & 3 & 2.38 & 2.39 \\
\cline { 2 - 9 } & 90 & 30 & 5 & 2 & 8 & 3 & 2.72 & 2.72 \\
\hline
\end{tabular}

\section{Summary}

By research about connotation principles and tools of the e-learning evaluation, give the evaluation quotas, based on this to set evaluation model, and use the model to have developed the system and evaluation of the effective was verified. Although the evaluation quotas are reasonable, but quota thresholds also need to further promote and verify, so as to be a reasonable reference for evaluation thresholds.

\section{Acknowledgements}

This work was financially supported by the Kunming Metallurgy College Science Foundation (13B02).

\section{References}

[1] Edward H, Perry: New Directions for Teaching and Learning (2012).

[2] Class Differences-Online Education in the United States on http://sloancon sor-tium.org /publications/survey/class differences.

[3] Zhao E-nuo. The number of people receiving modern distance education in China reached ten million.People’s daily, 2011, In Chinese.

[4] Hong-yan Wang, Wei-ping Hu: Distance Education in China, 2013, Vol8.30-34, In Chinese.

[5] Tian-min Feng, Shi-lu Zhang: Open Education Research, 2004, Vol3.34-36, In Chinese.

[6] Hong-hua Zhang, Gui-fang Cheng, Jun-qing Li: Modern Distance Education Research, 2005, Vol 6.26-29, In Chinese.

[7] Yu-bin Li, Shu-ning Wu, Qiao-hong Yao: Modern Distance Education, 2013, Vol5.34-39, In Chinese. 